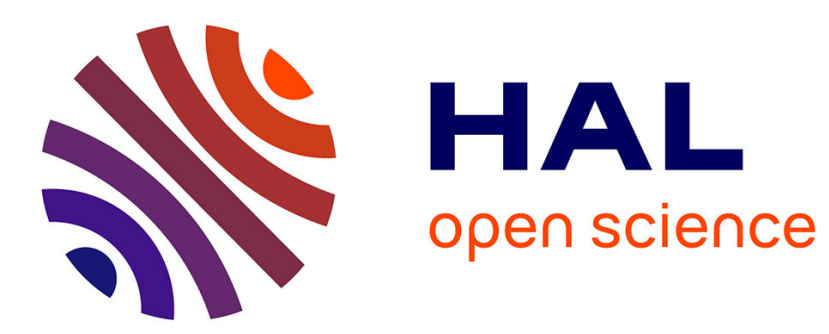

\title{
Incentives from stock option grants: a behavioral approach
}

\author{
Hamza Bahaji
}

\section{To cite this version:}

Hamza Bahaji. Incentives from stock option grants: a behavioral approach. 28ème conférence internationale de l'Association Française de Finance, May 2011, Montpellier, France. pp.CD Room. halshs-00681607

\section{HAL Id: halshs-00681607 https://shs.hal.science/halshs-00681607}

Submitted on 27 Mar 2012

HAL is a multi-disciplinary open access archive for the deposit and dissemination of scientific research documents, whether they are published or not. The documents may come from teaching and research institutions in France or abroad, or from public or private research centers.
L'archive ouverte pluridisciplinaire HAL, est destinée au dépôt et à la diffusion de documents scientifiques de niveau recherche, publiés ou non, émanant des établissements d'enseignement et de recherche français ou étrangers, des laboratoires publics ou privés. 


\title{
Incentives from stock option grants: a behavioral approach
}

\author{
Hamza BAHAJI * \\ Université de Paris Dauphine, DRM Finance
}

\begin{abstract}
Purpose - This paper analyzes the valuation of stock options from the perspective of an employee exhibiting preferences as described by Cumulative Prospect theory (CPT). In addition, it elaborates on their incentives effect and some implications in terms of design aspects.

Design/methodology/approach - The paper draws on the CPT framework to derive a continuous time model of the stock option subjective value using the certainty equivalence principle. Numerical simulations are used in order to analyze the subjective value sensitivity with respect to preferences-related parameters and to investigate the incentives effect.

Findings - Consistent with a growing body of empirical and experimental studies, the model predicts that the employee may overestimate the value of his options in-excess of their risk-neutral value. Moreover, for typical setting of preferences parameters around the experimental estimates, and assuming the company is allowed to adjust existing compensation when making new stock option grants, the model predicts that incentives are maximized for strike prices set around the stock price at inception. This finding is consistent with companies' actual compensation practices. Finally, the model predicts that an executive who is subject to probability weighting may be more prompted than a risk-neutral executive to act in order to increase the firm's assets volatility.

Originality/value - This research aims to propose an alternative theoretical framework for the analysis of pay-toperformance sensitivity of equity-based compensation that takes into account a number of prominent patterns of employee behavior that Expected Utility theory cannot explain. It contributes to recent empirical and theoretical researches that have advanced CPT framework as a promising candidate for the analysis of equity-based compensation contracts.
\end{abstract}

JEL Classification: J33, J44, G13, G32, M12

Keywords: Stock options, Cumulative Prospect Theory, Incentives, Subjective value.

\footnotetext{
* DRM-Finance, Université de Paris Dauphine, Place du Général du Lattre de Tassigny, 75 775, Paris Cedex 16, France. E-mail: hbahaji@yahoo.fr. Acknowledgements: the author is grateful to Clotilde NAPP, Jean-François CASTA, Jacques HAMON, Farhat SELMI and Khalid ARDEM for their valuable comments
} 


\section{Introduction}

Instead of an increasing interest for restricted stock and performance unit plans, the 2006 Hewitt Associates Total Compensation Measurement survey has revealed that stock options are still the most prevalent long term incentive vehicle ${ }^{1}$. The stated argument for the large use of executive stock options is that they align the interests of executives and shareholders since they provide incentives for the manager to act in order to increase the firm value. The use of stock options has even overtaken the traditional arena of executive population. Actually, firms' compensation practices show that stock options are issued to reward non-executive employees as well. This may seem puzzling at first sight in that the agency argument underlying the use of stock options is no more reliable under the nonexecutive employees view because the formers are unlikely to influence the firm value by their decisions (Spalt, 2008). Nevertheless, issuance of non-executive stock options results obviously from an agreement between the firm and the employee upon the terms of the compensation involving stock options, which means that employees may be interested in stock options. In order to figure out the reason why stock options may be attractive to employees it is crucial to assess the utility they receive from them. Moreover, understanding how employee evaluates its stock options (i.e. their subjective value) allows assessing their incentive power and the implied employee behavior in terms of risk taking.

Most of the theoretical literature on stock options relies on the Expected Utility theory (EUT henceforth) framework to derive models of option value from the employee perspective. These models predict that the nontransferability of the options and the hedging restrictions faced by the employee make him value his options below their issuance cost born by the company (i.e. their risk neutral value). A seminal work by Lambert et al (1991) has introduced a general theoretical framework to analyze the valuation of equity based compensation contract from a manager's perspective. The authors studied stock option contracts as a specific example. They used the certainty-equivalence principle to derive the so-called subjective value model. Their model assumes that the manager is a risk-averse agent with a power utility function and that he integrates his stock options in his global wealth assessment process. They proved that the subjective value decreases in risk aversion and increases in the manager diversification with respect to the company specific risk. Moreover, they showed that stock options may not provide incentives for a risk-averse manager to select actions that increase the variance of the company stock price. Hall and Merphy (2000, 2002) followed the same approach to analyze the risk-adjusted value of executive stock options along with their pay-toperformance sensitivity. Their major findings provide an economic rational to observed equity based compensation practices while perhaps troubling from an efficiency perspective. Mainly, they showed that pay-to-performance incentives from stock options, when these are granted as an add-on to existing

\footnotetext{
${ }^{1} 80 \%$ of the responding participant companies to the survey have reported that stock option grants represent in 2006 , on average, about $54 \%$ of their global long-term incentives.
} 
compensation, are typically maximized by setting their exercise price around the stock price at inception. In contrast, when options grants are assumed to be accompanied by reductions in cash compensation, their model predicts that restricted stocks provide much higher incentives for executives to increase the firm value and may then be preferred to stock options. Henderson (2005) has built on the previous works to examine the effect on valuation and incentives of market risk and firm-specific risk. She proposed a continuous time utility-based model to value stock options from the manager's perspective. A prominent assumption in his model is allowing the executive to invest the remainder of his wealth (excluding stock options) in the market portfolio ${ }^{2}$ and a risk-free asset. In particular, her results suggest that stock options do not provide incentives to increase total risk, but the beta of the company instead. She also finds that incentives decrease in firm-specific risk whilst they may either decrease or increase in market risk depending on other factors. In addition, similar to Hall and Murphy (2002), the author's model supports the grant of restricted stocks rather than stock options under efficient contracting framework.

A common finding of the EUT-based models is that the stock options value to a risk-averse undiversified employee is strictly lower than the value to a risk-neutral well diversified outside investors. This is nevertheless in stark contrast to several surveys and empirical findings documenting that employees may value their options above their risk-neutral value (i.e. the so-called Black Scholes value). Lacker's and Lambert's (2001) research based on a survey of Knowledge@Wharton readers revealed that managers value their options substantially above the Black Scholes value (BS henceforth). Moreover, the survey revealed that younger managers have the most upward bias in the values they perceive from their options. According to the authors, these results suggest that managers do not fully understand the valuation of stock options or possibly their incentive effects. Another argument supporting managers may tend to overestimate their options value is provided by Yermack (1997). He argues that to the extent that company executives have superior information regarding company prospects and can time their option grants accordingly, they may actually value options higher than would outside investors do. Furthermore, relying on behavioral theories, recent researches have found evidence on employees drawing on heuristics and subject to psychological bias while valuing their options, which may lead them to overestimate the value of their options. For instance, Devers et al.(2007) study examines the effects of endowment and loss aversion on managers' subjective stock-option valuation. Their main findings show that managers endow value from granted unexercisable options in a way that they value them in excess of their objective value (i.e. BS value). In the same vein, Sawers et al.(2006) drew conclusions from an experiment involving MBA students consistent with the view that loss-averse managers subjectively overvalue stock options relative to

\footnotetext{
${ }^{2}$ Prior works by Detemple and Sundaresan (1999) and by Cai and Vijh (2004) have used trees approach tied to specific numerical schemes to study utility-based valuation of executive stock options when the executive can invest in the Market portfolio.
} 
restricted stocks and, therefore, will be less risk-seeking when awarded with stock options and more risk-seeking when endowed with restricted stocks.

Moreover, standard normative models fail to predict stock options as part of the compensation contract. Several quantitative studies taking place in principal-agent framework showed that EUTbased models predict optimal compensation contracts that do not contain convex instruments like stock options (Holmstrom and Milgrom, 1987; Dittmann and Maug, 2007). Consistent with these findings, studies focused on the effect of stock option and restricted stock grants on managerial effort incentives (Jenter, 2001; Hall and Murphy, 2002; Henderson, 2005) conclude that stock options are inefficient tools for creating incentives for risk-averse managers when they are granted by mean of an offset of cash compensation.

This paper analyzes the valuation of stock options and their incentives effect to an employee exhibiting preferences as described by Cumulative Prospect Theory (Tversky and Kahneman, 1992). It aims to propose an alternative theoretical framework for the analysis of pay-to-performance sensitivity of equity-based compensation that takes into account a number of prominent patterns of employee behavior that standard EUT cannot explain. Specifically, the key assumption underlying this work proceeds from Cumulative Prospect Theory (CPT hereafter) and states that the employee choices under risk display four main features. Firstly, instead of assessing outcomes based on their contribution to his final wealth, the employee assesses outcomes utility over gains and losses determined relative to a reference level or a benchmark. The second feature is loss-aversion. It conveys the experimental evidence that people are more sensitive to losses than they are to gains. In other words, losses loom larger than gains. The third feature consists in the principle according to which people choices display diminishing sensitivity to incremental gains and losses. The last piece is the nonlinear probability processing. It involves the well established tendency of individuals to overweight small probabilities of large gains ${ }^{3}$. I drew on this theoretical framework to derive a continuous time model of the stock option subjective value using the certainty equivalence principle. I then performed sensitivity analyses with respect to preferences-related parameters and found that loss aversion and probability weighting have countervailing effects. In particular, I showed that the more the employee is loss averse, the less would the option be worth to him. In addition, I proved that the option subjective value is increasing in probability weighting degree. My analyses also show that, for a given level of option moneyness, the subjective value of the option may lie strictly above the BS value when the effect of probability weighting tends to dominate that of loss-aversion. These results lead to the conclusion that the lottery-like nature of stock-options, combining large gains with small probabilities, may make them attractive to employees subject to probability weighting which is

\footnotetext{
${ }^{3}$ There exists a large literature comprising empirical and experimental applications of overweighting small winning probabilities. This literature include notably Thaler and Ziemba (1988), Kachelmeier and Shehata (1992), Cook and Clotfelter (1993), Loughran and Ritter (1995) and Jullien and Salanie (2000).
} 
consistent with the proposition that employee option value estimate may exceed the BS value (Lambert and Larcker, 2001; Hodge et al., 2006; Sawers et al., 2006; Hallock and Olson, 2006; Devers et al., 2007).

Furthermore, this work elaborates on incentives from stock options and on some implications in terms of design aspects. Following previous researches, I defined incentives as the first order derivative of the subjective value with respect to the stock price. A numerical analysis of the incentive function shows that stock option incentives are increasing in employee's degree of probability weighting and may even lie above incentives for a risk-neutral individual. Moreover, I considered the incentive effects of setting the strike price of the option above or below the stock price at inception. In this analysis, I relied on Hall's and Murphy's (2002) methodology in solving for the exercise price that maximizes incentives holding constant the company cost of granting the options. Similar to their approach, I explored two situations. In the first situation, I assumed that the firm is precluded from changing any component of the employee compensation package. In this case, the model predicts that, when the effect of probability weighting prevails (i.e. dominates that of loss-aversion), incentives could be infinitely increased by granting more and more options at higher and higher strikes, which suggests that employee would be much more interested in premium options instead of discount options. However, when loss-aversion effect dominates, the model predicts that incentives are maximized within strike price ranges that may include the grant date stock price depending on the level of loss-aversion. In the second situation, the company is assumed to be allowed to adjust existing compensation when making new stock option grants. For typical setting of preferences parameters around the experimental estimates from CPT (Tversky and Kahneman, 1992), the model predicts that incentives are maximized for strike prices set around the stock price at inception, which is consistent with companies' actual compensation practices. Additional analyses suggest also that loss-averse employees who are not subject to probability weighting, or even with very low degrees of probability weighting, receiving options at high exercise price would willingly accept a cut in compensation to receive instead deep discount options or restricted shares for those of them displaying more lossaversion. This result is broadly consistent with Hall and Murphy (2002) and Henderson (2005) findings for non-diversified risk-averse employees.

The last item discussed in this paper is the risk taking incentives implied by stock option grants. Similar to previous studies, I defined incentives for risk taking as the first order derivative of the subjective value with respect to stock price returns volatility. The first essential result from this analysis is that incentives for risk taking are increasing with probability weighting degree. In fact, probability weighting leverages the positive effect of volatility on the subjective value through the convexity of the option payoff. Another important finding from the model is that an optioncompensated executive subject to probability weighting may be more prompted than a risk-neutral executive to act in order to increase assets volatility. Moreover, consistent with findings from EUT- 
based models, the CPT model predicts that a loss-averse probability-weighting-free executive may not prefer an increase in the variance of the company stock price return.

This work is motivated by recent empirical and theoretical researches on employee compensation incorporating CPT-based models. These models have proved successful in explaining some observed compensation practices, and specifically the almost universal presence of stock options in the executive compensation contracts that EUT-based models have difficulties accommodating their existence. Therefore, they have advanced CPT framework as a promising candidate for the analysis of equity-based compensation contracts. This literature includes in particular Dittmann et al. (2008) who developed a stylized principal-agent model that explain the observed mix of restricted stocks and stock options in the executive compensation packages. It also includes Spalt (2008) who used the CPT framework, and especially the probability weighting feature, to prove that stock options may be attractive to a loss-averse employee subject to probability weighting. He then explained the puzzling phenomenon that riskier firms are prompted to grant more stock-options to non-executive employees.

This article proceeds as follows. The first section describes the features of stock option value from the perspective of a representative employee with preferences as described by CPT. Throughout this paper, we will refer to this employee as a "CPT employee". This section provides also numerical analyses on the model sensitivity to preferences-related parameters. The next section introduces incentive effects of stock options for a CPT-employee and examines some design implications in terms of strike price setting. The risk taking incentives question is explored in the third and last section. Appendices provide proofs of the propositions in the first section.

\section{Stock option value from a CPT-employee perspective.}

In this section, I develop a base-case model for analyzing the value of the stock-option contract from the perspective of a representative employee with CPT-based preferences (subjective value henceforth). Specifically, I assume that the employee is granted a European call option on the company's stock, denoted by $S$, with maturity date $t=T$ and strike price $K$. These are the traditional features of executive stock options as reported in Johnson and Tian (2000) and used by prior studies focused on stock option incentives (Lambert et al., 1991; Hall and Murphy, 2002 ; Henderson, 2005). Often in practice, stock options are Bermudan-style options. Thus, my model relies on a naïve setting in that it ignores complications related to early exercise or forfeitures.

\subsection{Theoretical framework.}

\subsubsection{Stock-option contract.}


The stock option contract is issued in $t=0$. The contract payoff at expiry, $t=T$, is $h_{T}=\left(S_{T}-K\right)^{+}$.

I make the assumption that the employee is not allowed to short-sell the company stock and that he can earn the risk-free rate $r$ from investing in a riskless asset. Moreover, the price dynamic of the stock is given by a geometric Brownian motion represented by the following SDE:

$d S_{t}=(r-q) S_{t} d t+\sigma S_{t} d Z_{t}$

Where $Z_{t}$ is a standard Brownian motion with respect to the probability measure $I P . \sigma^{2}$ and $q$ are respectively the total variance of the stock price returns and the dividend yield.

\subsubsection{Risk preferences.}

Following Tversky and Kahneman (1992), I consider that, to each gamble with a continuous random outcome $y \in I R$ which the probability density function is denoted by $f(y)$, the employee assigns the value:

$$
E_{\Omega}(y)=\int_{I R} v_{\theta}(y) d \Omega(f(y))
$$

Note that the expectation $E_{\Omega}($.$) is a function of two distinct functions. The first function, v_{\theta}($.$) ,$ called the value function, is assumed of the form:

$$
v_{\theta}(y)=\left\{\begin{array}{c}
(y-\theta)^{\alpha} ; y \geq \theta \\
-\lambda(\theta-y)^{\alpha} ; y<\theta
\end{array} \text {, where } 0<\alpha \leq 1 \text { and } \lambda \geq 1\right.
$$

This formulation has some important features that distinguish it from the standard utility specification. First, the utility is defined over gains and losses assessed based on the reference point denoted by $\theta$. This idea was proposed first by Markowitz (1952). As pointed out by Barberis and Thaler (2003), it fits naturally the way people perceive attributes, in everyday life, relative to their previous levels rather than in absolute fashion. The second important feature is the shape of the value function. While it is convex over losses, it is concave over gains, which represents the observation from psychology that people are risk averse over gains and become risk-seeking over losses. Moreover, the value function has a kink at the origin introduced by the parameter $\lambda \geq 1$. This feature, known as loss-aversion, gives a higher sensitivity to losses compared to gains. Finally, outcomes are 
treated separately from other components of wealth, which reflects the well-documented phenomenon of narrow framing ${ }^{4}$ (Thaler, 1999).

The second function, $\Omega_{a, b}($.$) , is called the weighting function. It applies to cumulative$ probabilities, represented by the cumulative probability function $F($.$) , in order to transform them into$ decision weights according to:

$$
\Omega_{a, b}(F(y))=\left\{\begin{array}{l}
\frac{-(1-F(y))^{a}}{\left(F(y)^{a}+(1-F(y))^{a}\right)^{\frac{1}{a}}} ; y \geq \theta \\
\frac{F(y)^{b}}{\left(F(y)^{b}+(1-F(y))^{b}\right)^{\frac{1}{b}}} ; y<\theta
\end{array} \quad \text { where } 0.28<a \leq 1 \text { and } 0.28<b \leq 1^{5}\right.
$$

This function stands for another piece of CPT, which is the nonlinear transformation of probabilities. Specifically, it captures experimental evidence on people overweighting small probabilities and being more sensitive to probability spreads at higher probability levels (e.g. a jump in probability from 0.7 to 0.9 would be more striking to individual than an equal-sized jump from 0.1 to 0.3 ). The degree of probability weighting is controlled separately over gains and losses by the weighting parameters $a$ and $b$ respectively. The more these parameters approach the lower boundary at 0.28 the more the tails of probability distribution are overweighted. For instance, when $a=b=1$, probability weighting assumption is relaxed. For simplicity, these parameters are assumed to be equal (i.e. $a=b$ ) and the weighting function will be denoted $\Omega_{a}($.$) in the rest of this paper. Finally, it is$ worth mentioning that this function (i) infinitely-overweights infinitesimal probabilities since $\lim _{p \rightarrow 0} \frac{\Omega_{a}(p)}{p}=\infty$ and (ii) infinitely-underweights near-one probabilities in that $\lim _{p \rightarrow 1} \frac{\Omega_{a}(1-p)}{1-p}=\infty$.

\subsection{Stock option subjective value.}

\subsubsection{The model.}

\footnotetext{
${ }^{4}$ Narrow framing refers to people tendency to treat individual gambles separately from other portions of wealth. It stands for an important feature of Mental Accounting, the mental process by which individuals formulate problems for themselves (e.g. the way they code outcomes). Mental accounting is captured in CPT via the nonlinear shape of the value function.

${ }^{5}$ The lower boundary at 0.28 is a technical condition to insure that $\frac{\partial \Omega_{a, b}(p)}{\partial p}$ is positive over ]0,1[ as required by the following first order condition: $(a-1) p^{a}+(a(1-p)+p)(1-p)^{a} \geq 0$.
} 
In order to estimate the subjective value of the stock option contract described above, I use the certainty equivalent approach similar to that adopted by Spalt (2008). In particular, this value is defined as the cash amount, $C_{\theta, a}$, that leaves the employee indifferent between this amount and the uncertain payoff of the contract, $h_{T}$, irrespective of the composition of the remainder of his private wealth. Formally, $C_{\theta, a}$ is the solution of the following equation:

$$
\begin{aligned}
v_{\theta}\left(C_{\theta, a} e^{r T}\right) & =E_{I P_{\Omega_{a}}}\left\{v_{\theta}\left(h_{T}\right)\right\} \\
& =\int_{I R} v_{\theta}\left(h_{T}\right) d \Omega_{a}\left(F\left(S_{T}\right)\right)
\end{aligned}
$$

The left-hand side of the equation above represents the benefit for the employee from receiving the cash amount $C_{\theta, a}$ instead of the stock option contract at the inception of the latter. This amount is assumed to be placed into the risk-free asset over the whole lifetime $T$ of the stock option contract. The other side of the equation gives the expected utility to the employee from receiving the risky payoff implied by the value function $v_{\theta}($.$) . Here, the expectation E_{I P_{\Omega_{a}}}$ relies on the transformed probability measure $I P_{\Omega_{a}}$.

Let $E_{\theta, a}$ represent the expectation in the right-hand side of (5). It follows from (5) and (3) that

$C_{\theta, a}=\left\{\begin{array}{l}\left(\theta+\left(E_{\theta, a}\right)^{\frac{1}{\alpha}}\right) e^{-r T}, \text { if } E_{\theta, a} \geq 0 \\ \left\{\begin{array}{l}\left.\left(-\frac{1}{\lambda} E_{\theta, a}\right)^{\frac{1}{\alpha}}\right) e^{-r T}, \text { otherwise }\end{array}\right.\end{array}\right.$

Where $E_{\theta, a}$ should write:

$$
E_{\theta, a}=I_{\theta, a}^{1}+I_{\theta, a}^{2}+I_{\theta, a}^{3}
$$

With:

$$
\begin{aligned}
& I_{\theta, a}^{1}=\int_{l_{1}}^{+\infty}(g(x)-K-\theta)^{\alpha} \Omega_{a}^{\prime}\left(\int_{-\infty}^{x} \varphi(u) d u\right) \varphi(x) d x \\
& I_{\theta, a}^{2}=\int_{l_{2}}^{l_{1}}-\lambda(K+\theta-g(x))^{\alpha} \Omega_{a}^{\prime}\left(\int_{-\infty}^{x} \varphi(u) d u\right) \varphi(x) d x
\end{aligned}
$$


$I_{\theta, a}^{3}=-\lambda \theta^{\alpha} \Omega_{a}\left(\int_{-\infty}^{l_{2}} \varphi(x) d x\right)$

$g(x)=S e^{\left(r-q-\frac{\sigma^{2}}{2}\right) T+\sigma \sqrt{T} x}$

$l_{1}=-\frac{\ln \left(\frac{S}{K+\theta}\right)+\left(r-q-\frac{\sigma^{2}}{2}\right) T}{\sigma \sqrt{T}}$

$l_{2}=-\frac{\ln \left(\frac{S}{K}\right)+\left(r-q-\frac{\sigma^{2}}{2}\right) T}{\sigma \sqrt{T}}$

Here $\varphi($.$) is the Gaussian density function and \Omega_{a}^{\prime}(p)=\frac{\partial \Omega_{a}(p)}{\partial p}$ is the first-order partial derivative of $\Omega_{a}($.$\left.) which is defined over \right] 0,1[$ as follows:

$\Omega_{a}^{\prime}(p)=\left\{\begin{array}{l}\left.\frac{(1-p)^{a-1}}{\left(p^{a}+(1-p)^{a}\right)^{\frac{1}{a}}} \mid a+\frac{(1-p)\left(p^{a-1}-(1-p)^{a-1}\right)}{p^{a}+(1-p)^{a}}\right) ; p \geq \int_{-\infty}^{l_{1}} \varphi(x) d x \\ \left|\frac{p^{a-1}}{\left(p^{a}+(1-p)^{a}\right)^{\frac{1}{a}}}\right| a-\frac{p\left(p^{a-1}-(1-p)^{a-1}\right)}{p^{a}+(1-p)^{a}} \mid ; p<\int_{-\infty}^{l_{1}} \varphi(x) d x\end{array}\right.$

\subsubsection{Reference point set up.}

Although CPT specifies the shape of the value function around the reference point, it does not provide guidance on how people set their reference points. Neither does most of the psychological literature relying on the assumption according to which the reference point is the Status quo. Instead, this literature admits both the existence and the importance of non-status quo reference points since "there are situations in which gains and losses are coded relative to an expectation or aspiration level that differs from the status quo" (Kahneman and Tversky, 1979).

Research on the Disposition Effect $t^{6}$ has paid greater attention to non-status quo reference points (Shefrin and Statman, 1985 ; Heisler, 1998 ; Odean, 1998a ; Gneezy, 1998). These studies have found

\footnotetext{
${ }^{6}$ Disposition effect is a term coined by Shefrin and Statman (1985) to refer to the tendency of individual investors to hold loser stocks and sell winner stocks defined relative to a purchase price reference point.
} 
strong evidence that reference points are set in a dynamic fashion. In particular, Gneezy (1998) documented that maxima are more effective predictors than are purchase prices.

More specifically, in studding exercise behavior of stock options holders, Huddart and Lang (1996), Heath et al (1999) and Bahaji (2009) have shown empirically that exercise activity is linked to share price historical maxima. These findings are consistent with employee exercise decisions take into account the level of share price with respect to non-status quo reference points.

In principle, employee would update the reference point in a way that fits with his own expectations regarding the underlying share price at expiry. Intuitively, the employee could estimate the intrinsic value of the option based on his future share price forecasts as he can rely on the Black Scholes value of the option disclosed by the firm. Following Spalt (2008), I consider that the reference point parameter in the model, $\theta$, is the BS value ${ }^{7}$. Beyond the argument of empirical evidence on employee exercise behavior depending on non-status quo reference points, this assumption is supported by firms common practices in terms of stock option compensation. Most of stock-option designers use the BS model in order to estimate the value of stock options as constituents of the total compensation package. This value is usually announced to the employee at the inception of the options. Moreover, the BS model is recommended in the FASB and the IASC guidelines for determining the fair value of stock options (i.e. the amount an outside investor, with no hedge restrictions, would pay for the option) that needs to be disclosed in the financial statements. These statements, comprising the BS value of the stock options, are provided to shareholders as well as stakeholders including employees.

\subsubsection{The impacts of preferences-related parameters: a numerical analysis.}

To provide a concrete outline on the profile of the subjective value yielded by the model relative to the risk neutral value profile, I performed a numerical analysis ${ }^{8}$ of the value of a 4 -year call option ( $T=4$ ) with a strike price $K=100$. For the remaining option-related parameters, the figures were computed assuming no dividend payments $(q=0 \%), \sigma=30 \%$ and $r=3 \%$. Moreover, I set the curvature parameter of the value function $(\alpha)$ and the loss aversion coefficient $(\lambda)$ to respectively 0.88 and 2.25 based on experimental estimates from CPT (Tversky and Kahneman, 1992).

\footnotetext{
${ }^{7}$ To be more precise, the value used here is the expectation of the option payoff at expiring yielded by the BS model (i.e. the nondiscounted BS value). Consistent with this specification, the probability measure $I P$ used to derive the subjective value in (6) is the risk neutral probability measure. Moreover, ignoring the probability weighting feature (i.e. $a=1$ ), this setting allows the subjective value implied by the model to converge towards the risk neutral value (i.e. BS value) when the preferences of the employee tend to risk neutrality (i.e. $\alpha=\lambda=1$ ).

${ }^{8}$ The integrals in (6.2), (6.3) and (6.4) were computed numerically.
} 
Furthermore, in order to calibrate the probability weighting function, I used three different values of the parameter $a$ within the range of values estimated in the experimental literature 9 .

Figure 1 depicts the option value as a function of the stock price. The three blue curves represent the value profiles from the perspective of three CPT employees with the same value function and different degrees of probability weighting. At first sight, depending on the degree of probability weighting and the option moneyness $\left(\frac{S}{K}\right)$ the subjective value could lie either under or below the BS value. In contrast, standard EUT-based models predict that the option value from a risk-averse employee perspective is systematically lower than the risk-neutral value (Hall and Murphy, 2002; Henderson, 2005). These preliminary results are consistent thought with some empirical findings suggesting that frequently employees are inclined to overestimate the value of their stock-options compared with the BS value (Lambert and Larcker , 2001 ; Hodge et al., 2006 ; Sawers et al., 2006 ; Hallock and Olson, 2006 ; Devers et al., 2007).

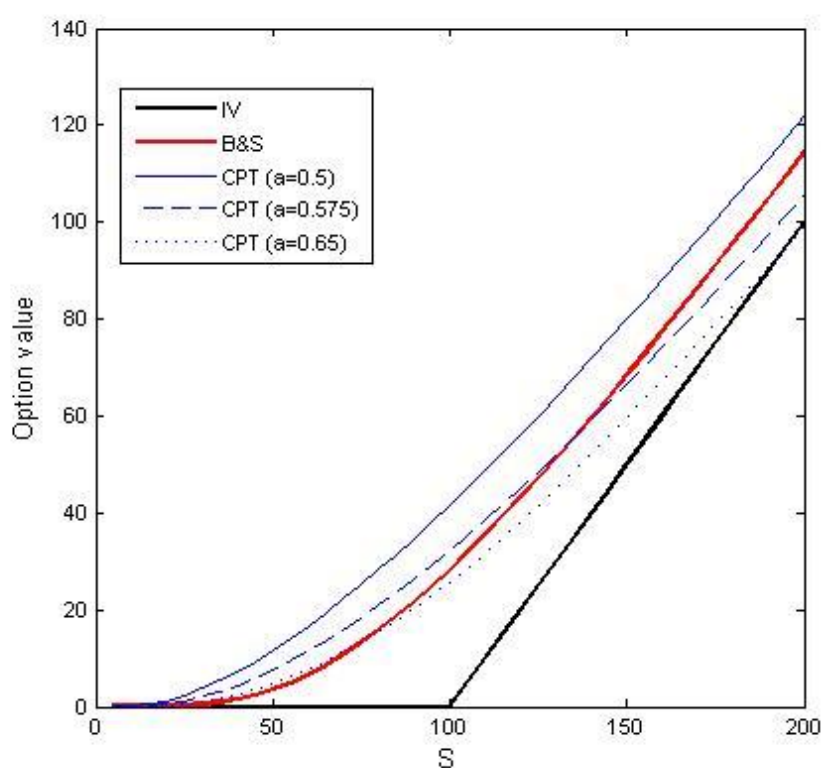

Figure-1: Option value against the stock price. This figure is a plot of the subjective value computed under different probability weighting parameters (the blue curves). It illustrates the profile of the subjective value compared to that of the risk neutral value (red curve). The Parameters used are: $\mathrm{T}=4 ; \mathrm{K}=100 ; \sigma=30 \% ; \mathrm{r}=3 \% ; \mathrm{q}=0 \% ; \lambda=2.25 ; \alpha=0.88$.

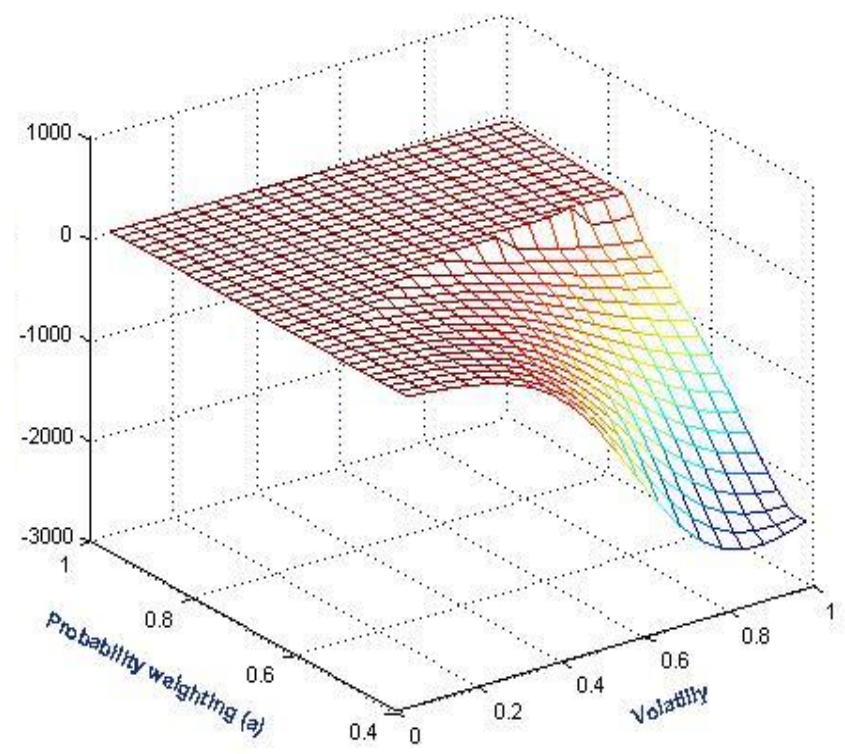

Figure-2: Sensitivity to probability weighting. This figure is a plot of the partial derivative of the subjective value with respect to "a" against both "a" and the stock price volatility " $\sigma$ ". It exhibits the local effect of probability weighting given the payoff distribution skewness captured by " $\sigma$ ". The derivative was computed numerically based on the following parameters: $\mathrm{T}=4 ; \mathrm{K}=\mathrm{S}=100 ; \mathrm{r}=3 \% ; \mathrm{q}=0 \% ; \lambda=2.25 ; \alpha=0.88$.

\footnotetext{
${ }^{9}$ Tversky and Kahneman (1992) got 0.65 on average ( $a=0.61$ for gains and $b=0.69$ for losses). These results are corroborated by Abdellaoui's (2000) findings ( $a=0.60$ for gains and $b=0.70$ for losses, hence an average of 0.65 ). In addition, Camerer and Ho (1994) obtained $a=0.56$ for gains whereas Gonzales and $\mathrm{Wu}(1996)$ and Bleichrodt and Pinto (2000) found $\mathrm{a}=0.71$ and $\mathrm{a}=0.67$ respectively.
} 
The results presented in figure 1 show that the option subjective value is increasing in probability weighting degree (i.e. decreasing in parameter $a$ ). Actually, given the asymmetric profile of the option payoff, the expectation $E_{\theta, a}$ in the subjective value formula (6) is positively affected by the emphasis put on the tail of the payoff distribution which is governed by the parameter $a$ : the lower $a$ the more overweighed will be small probabilities and the more underweighted will be medium to large probabilities. This lottery-like nature of an option, combining large gains with small probabilities, may make it attractive to a CPT employee subject to probability weighting. This preliminary outcome leads to proposition 1 which stats that:

Proposition 1: the value of the stock option contract to a CPT-employee is increasing with respect to his degree of probability weighting (i.e. is decreasing with respect to a).

(Proofs are provided in appendix A)

Moreover, the effect of probability weighting is expected to increase with the skewness of the distribution of the underlying stock price, which is captured by the volatility parameter $\sigma$ given the Log-normality assumed in the model. In order to show that, I performed a numerical analysis of the sensitivity of the subjective value to the probability weighting degree as a function of the volatility $\sigma$ and the parameter $a$. This sensitivity is defined as the partial derivative of subjective value with respect to $a\left(\frac{\partial C_{\theta, a}}{\partial a}\right)$. The results are reported in figure 2 in the form of a graph. It shows that the sensitivity to parameter $a$ is negative and locally decreasing in volatility. That means that the more the share price is volatile the more the option will be attractive for a CPT employee subject to probability weighting. This supports Spalt's (2008) findings that the effect of probability weighting provides an economic rationale to riskier firms (i.e. more volatile firms) for granting more stock options to nonexecutive employees.

Furthermore, I investigate the effect of loss aversion on the subjective value. The variable of interest here is $\lambda$. In an analogical sense with the EUT framework, the option value from the perspective of a loss-averse employee is expected to decrease with his degree of loss-aversion. To verify this I computed numerically the first order derivative with respect to $\lambda\left(\frac{\partial C_{\theta, a}}{\partial \lambda}\right)$ crossed over various levels of $\lambda$ and moneyness, ranging from 0.05 to 1 and from 5\% to $200 \%$ respectively. The outcome is reported in figure 3 . It shows that the sensitivity to loss aversion is negative and locally decreasing in moneyness. That means that the more the employee is loss averse, the less would the option be worth to him. This conclusion is taken up in proposition 2 hereafter: 
Proposition 2: the value of the stock option contract to a CPT-employee is decreasing with respect to his degree of loss-aversion (i.e. a decreasing function of $\lambda$ ).

(Proofs are provided in appendix B)

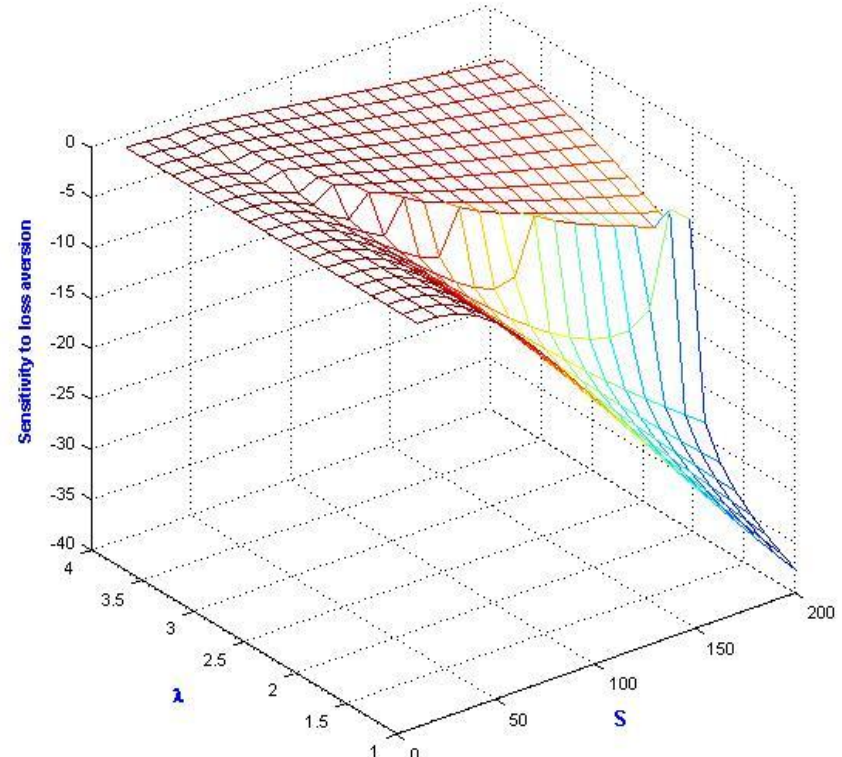

Figure-3: Sensitivity to loss aversion. This figure is a plot of the partial derivative of the subjective value with respect to " $\lambda$ " against both " $\lambda$ " and the stock price " $S$ ". It exhibits the local effect of loss aversion given the option moneyness. The derivative was computed numerically based on the following parameters: $\mathrm{T}=4$; $\sigma=30 \% ; \mathrm{K}=100 ; \mathrm{r}=3 \% ; \mathrm{q}=0 \%$; $\mathrm{a}=0.65 ; \alpha=0.88$.

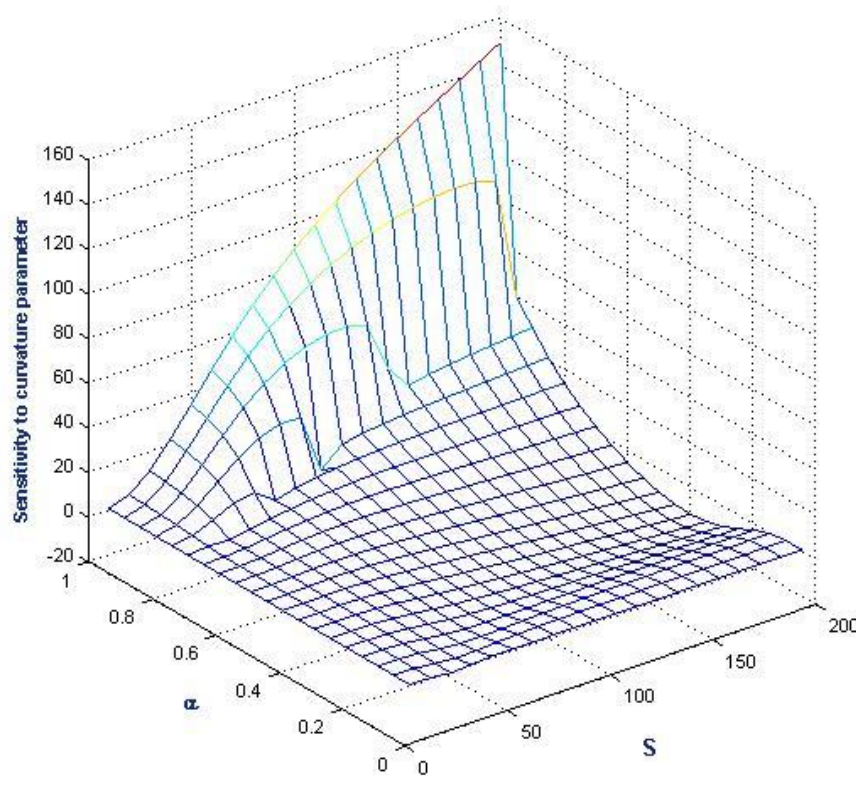

Figure-4: Sensitivity to the curvature parameter. This figure is a plot of the partial derivative of the subjective value with respect to " $\alpha$ " against both " $\alpha$ " and the stock price " $S$ ". It exhibits the local effect of the curvature parameter given the option moneyness. The derivative was computed numerically based on the following parameters: $\mathrm{T}=4 ; \sigma=30 \% ; \mathrm{K}=100 ; \mathrm{r}=3 \% ; \mathrm{q}=0 \%$; $\mathrm{a}=0.65 ; \lambda=2.25$.

I performed a similar analysis in order to get a view on the effect of the curvature parameter $\alpha$. In the same way, I assessed locally the first order derivative with respect to $\alpha$ within a range of values from 0.05 to 1 and using share prices ranging from 10 to 200. Figure 4 shows that this derivative is locally increasing with the option moneyness for values of $\alpha$ above say 0.75 . It also shows broadly that the subjective value is an increasing monotone function of $\alpha$ over a range of values around the experimental estimate of 0.88 (from 0.7 to 1 ) irrespective of the option moneyness.

\section{Incentives from stock-options.}

Stock-options are incentive tools used within a principal-agent relationship to align the interests of the agent (employee) on those of the principal (shareholders). The shareholders grant stock options in 
order to provide the employee with incentives to make efforts that enhance the value of the firm, and thus their own wealth. Indeed, assuming that employees are aware of how their actions affect the share price, option holdings will prompt them to make efforts that increase share price. Therefore, the incentive from a single option grant will depend on the degree of the sensitivity of the subjective value to the stock price.

\subsection{The incentive measure.}

Following Jensen and Murphy (1990), Hall and Murphy (2000, 2002) and others, I defined the incentive effect as the first order derivative of the subjective value with respect to share price $\left(\frac{\partial C_{\theta, a}}{\partial S}\right)$ which defines how the value from the employee perspective changes with an incremental change in the stock price. As we can see in figure 5, which is a plot of $\frac{\partial C_{\theta, a}}{\partial S}$ for three values of $a$, incentives are greatest for in-the-money ${ }^{10}$ options. Also, the incentive effect is increasing with the degree of probability weighting. Another observation that can be made from figure 5 is that, for sufficiently high level of probability weighting, the option can give much more incentive to increase stock price than is reflected by the BS delta. This is consistent with my previous finding that the subjective value can overstate the BS value. Note that, consistently with the EUT-based models, when the employee process probabilities in a linear way $(a=1)$ - which means that the probability weighting assumption is relaxed and only loss-aversion matters - the incentives lie strictly under the BS delta whatever the level of the option moneyness. That is to say that the options are less attractive for both risk-averse employee and loss-averse employee who are not subject to probability weighting. The analysis in figure 6 supports this. It shows that, with $a$ hold constant at 0.65 , incentives are decreasing in lossaversion. Conversely, with loss-aversion parameter $\lambda$ set to 1 , which means that the loss-aversion effect is neutralized, incentives for a representative loss-neutral employee, with a degree of probability weighting equal to experimental estimate of 0.65 , overstate the BS delta.

\footnotetext{
${ }^{10}$ The terminology "at-the-money" is referring to stock-options with an exercise price equal to the stock price at inception. The expressions "Out-of- the-money" and "In-the-money" are also used throughout the paper to refer to options with strike price respectively below and above the grant date stock price.
} 


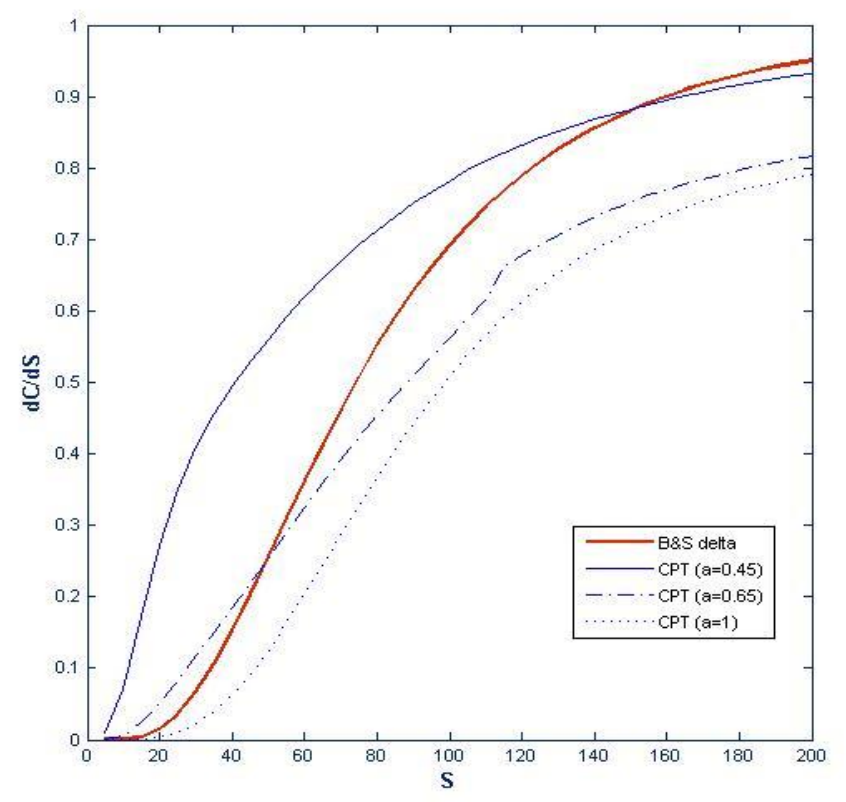

Figure-5. The effect of probability weighting on stock-option incentives. This figure is plots of the partial derivative of the subjective value with respect to stock price "S" against the option moneyness. It exhibits the combined effects of probability weighting and option moneyness on incentives. The derivatives were computed numerically assuming three different levels of probability weighting (see the legend above) and holding the remaining parameters constant at the following values: $\mathrm{T}=4$; $\sigma=30 \% ; \mathrm{K}=100 ; \mathrm{r}=3 \% ; \mathrm{q}=0 \% ; \lambda=2.25 ; \alpha=0.88$.

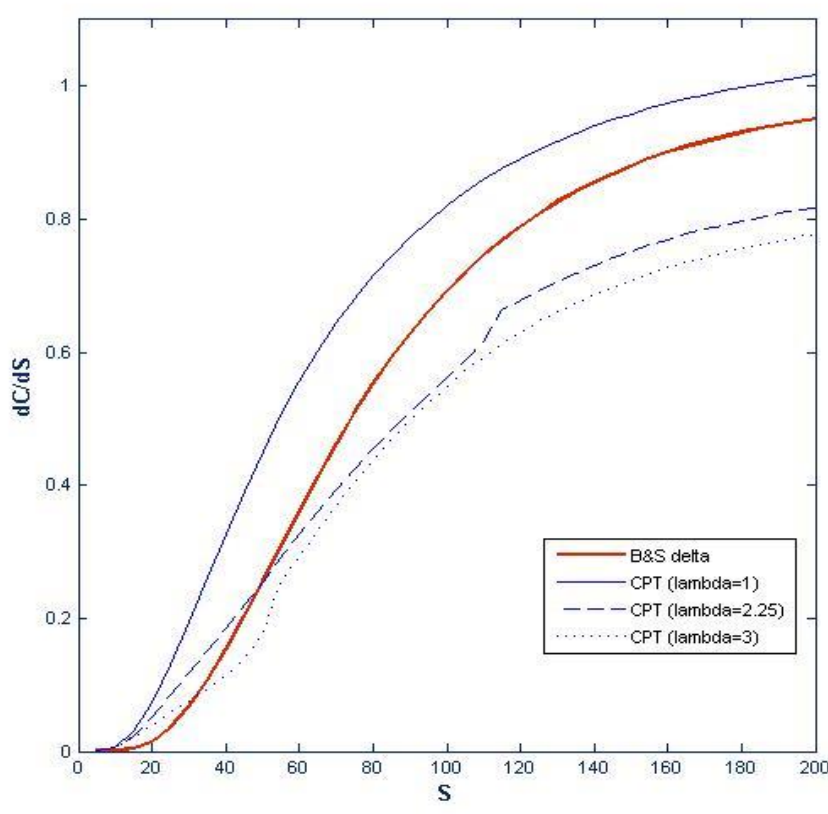

Figure-6. The effect of loss-aversion on stock-option incentives. This figure is plots of the partial derivative of the subjective value with respect to stock price "S" against the option moneyness. It exhibits the combined effects of loss-aversion and option moneyness on incentives. The derivatives were computed numerically assuming three different levels of loss-aversion (see the legend above) and holding the remaining parameters constant at the following values: $\mathrm{T}=4 ; \sigma=30 \% ; \mathrm{K}=100 ; \mathrm{r}=3 \% ; \mathrm{q}=0 \%$; $\mathrm{a}=0.65 ; \alpha=0.88$.

\subsection{Implications for stock option design: optimal strike price.}

Setting the strike price of standard stock options boils down to defining the threshold against which the performance is assessed and, consequently, to determining the likelihood of a final payout. As we have just noticed from figure 5 and figure 6 , incentives increases in the option moneyness and, equivalently, decreases with strike price. In parallel, from the shareholders perspective, granting inthe-money options is much more costly than granting out-of-the money or at-the-money options (recall figure 1). This leads the firm to a trade-off to make when setting the exercise price of the options in the sense that, holding his cost unchanged, she could either grant fewer options at a low strike price or increase the grant size at higher exercise price.

I relied on the methodology from Hall and Murphy (2002) in figuring out the optimal exercise price satisfying the double purpose of maximizing incentives and holding constant the firm's cost of granting options. I also considered two situations. In the first situation, the firm does not adjust the existing compensation package when grating additional stock options. Thus, these additional options are considered as a pure add-on to existing compensation. In the second situation however, the employee and the firm are allowed to bargain efficiently over the terms of the compensation. Thus, the 
firm is assumed to fund additional options by an adjustment to other compensation components that leaves the employee indifferent between his initial package and the new package including the additional grant.

\subsubsection{Situation 1: Option grant without a compensation offset.}

When the firm is not allowed to adjust the existing compensation package, the optimal strike price that maximizes incentives for a given amount of firm cost is the solution to the following constrained optimization problem:

$$
\max _{K} \frac{\partial n C_{\theta, a}(K)}{\partial S} \text { such that } n \pi(K)=c
$$

Where $\frac{\partial n C_{\theta, a}(K)}{\partial S}$ denotes the incentives from receiving $n$ options with a strike price $K$ and $\pi(K)$ the per-unit cost or the BS value of one option.

The optimization problem in (7) is solved numerically by varying the parameter $K$. First, the BS value is computed for a given $K$ which enable to determine the grant size $n$ that leaves the firm cost constant at $c$ in accordance with the constraint in (7). Then, the cost function $\frac{\partial n C_{\theta, a}(K)}{\partial S}$ is assessed based on $n$ and $K$. This procedure is reiterated recursively until the optimal value of $K$ is found.

I set the total cost for the firm at $c=€ 28333$ (hence a grant of $n=1000$ at-the-money options based on the retained option-related parameters). As reported in figure 7, I varied the preferencesrelated parameters $a$ and $\lambda$ within specific ranges in order to figure out the conditions under which an optimal strike may exist and the robustness of the model predictions. The chart on the left-hand side exhibits the total incentives from the grant as a function of the strike price and the probability weighting parameter with the loss-aversion held constant at $\lambda=2.25$. It shows that the convexity and the monotony of the total incentives function $\left(\frac{\partial n C_{\theta, a}(K)}{\partial S}\right)$ shift with the degree of probability weighting: while it is concave and non-monotone over the range of strike prices for low levels of probability weighting ( $a \geq 0.906$ ) it becomes convex and monotonically increasing for higher levels. Moreover, for higher level of volatility, probability weighting is expected to affect more deeply the shape of total incentives function (recall figure 2).

Specifically, when the effect of probability weighting prevails (i.e. dominates that of loss-aversion), the model predicts that incentives could be infinitely increased by granting more and more options at higher and higher strikes. This result suggests that, if the employee is subject to a degree of probability 
weighting that could potentially lead him to overstate the value of the option in excess of the BS value, he would ask for the maximum number of options (as much options as the company could possibly grant him) at their (highest) breakeven strike: the higher the strike price, the more small probabilities of large gains there are, and the more valuable become options to him. Furthermore, this means that such an employee would be much more interested in premium options instead of discount options. Actually, although this result is in stark contrast with the common stock-based compensation practices that consist in granting broadly at-the-money options, it shouldn't be rejected without taking into account the other factors restricting the number of options the company could issue irrespective of their strike prices, such like capital dilution limits.

In addition, as we can notice from the plot in the middle of figure 7 , the effect of probability weighting on total incentives could be offset by an increasing loss-aversion. This time $\lambda$ is varied and $a$ held constant at 0.65 , which meets the experimental estimate. When the loss-aversion effect dominates, the total incentives function tends to non-monotone concave shapes, which means that it admits finite extremas. In particular, when probability weighting effect is neutralized by setting $a=1$ in other words, the employee is not subject to probability weighting - total incentives curve tends to flatten around the optimum (see the green curves on the right-hand side plot). This suggests that there exists a range of strike prices that yield quasi-similar incentives. For instance, with loss-aversion set at $\lambda=2.25$, optimal strike (as $\%$ of stock price at inception) is about $142 \%$ and lies within a range of values, from $121 \%$ to $153 \%$, that yield total incentives of about $€ 530$ (rounded figure). With $\lambda=6$ the optimal strike drops by almost 30\% (to 112\%) and total incentives are flat around the maximum value of $€ 450$ within the range from $91 \%$ to $111 \%$. Note that these results are consistent with Hall's and Murphy's (2000, 2002) findings relying on the EUT framework. Consistently, their work documented that incentive-maximizing strike price exists when the options are considered as an addon to existing compensation. In addition, they showed that total incentives are relatively flat around the maximum and that optimal strike price decreases for more risk-averse and less diversified employees. 

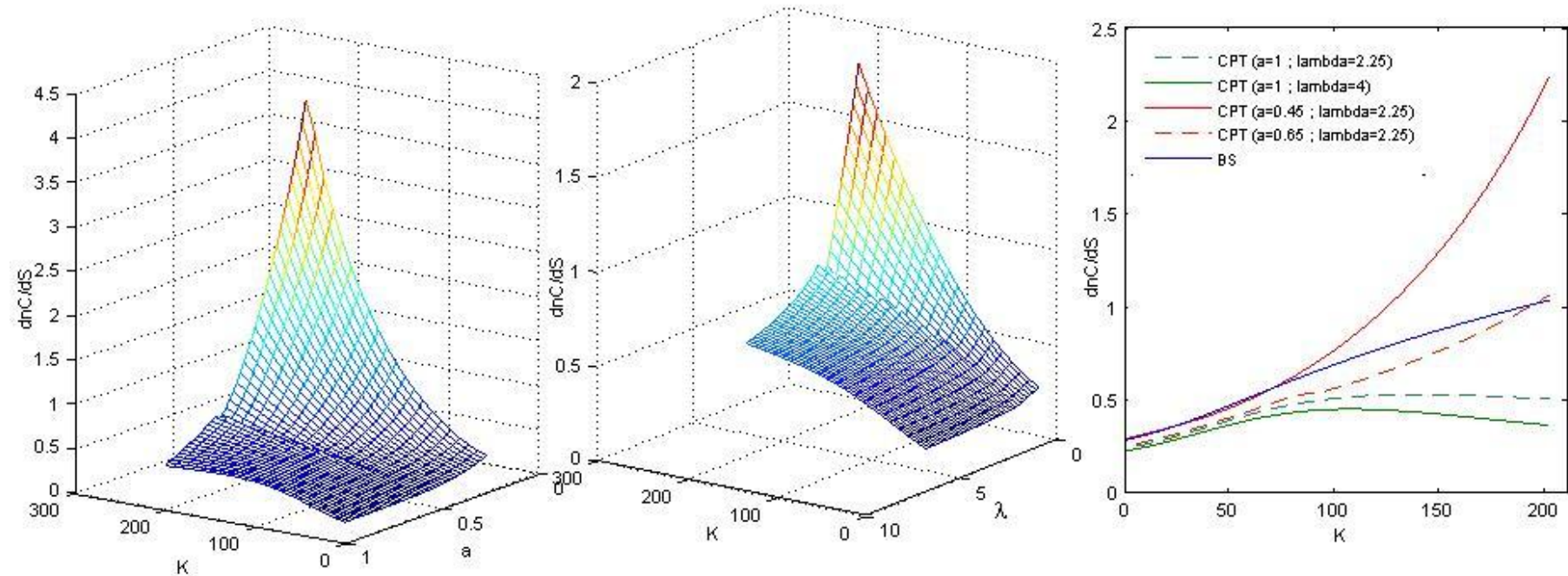

Figure-7. Incentives from options grant with total cost of $€ 28333$ assuming no adjustment to existing compensation package. This figure is plots of incentives (in $\mathrm{K} €$ ) from options grant for a given strike price holding the total BS value of the grant constant at $€ 28333$. Total incentives are defined as the partial derivative of the total subjective value of the grant with respect to stock price "S". The sub-figure on the left-hand side depicts total incentives as a function of the strike price and probability weighting parameter. That in the middle is a plot of total incentives against strike price and loss-aversion. The sub-figure on the right-hand side exhibits the combined effect of probability weighting and loss-aversion on the shape of total incentives as a function of strike price. The derivatives were computed numerically based on the following parameters: $\mathrm{T}=4 ; \sigma=30 \% ; \mathrm{S}=100 ; \mathrm{r}=3 \% ; \mathrm{q}=0 \% ; \alpha=0.88$.

\subsubsection{Situation 2: Option grant with an adjustment to existing compensation.}

Now, let's considerer that the company is allowed to make an efficient adjustment to existing compensation components (cash for example) in order to grant additional options to the employee. The impact of this adjustment should be neutral with regard to the total compensation cost for the company. Moreover, assuming this adjustment involves cash compensation, it must be attractive to the employee so that he'd be willing to give up some cash compensation against extra options grant. Therefore, it must leave the employee at his initial total subjective value of the compensation package. It follows that the strike price that maximizes total incentives for a given company cost is the solution of this following optimization problem:

$$
\max _{K} \frac{\partial n C_{\theta, a}(K)}{\partial S} \text { subject to } n \pi(K)-n C_{\theta, a}(K)=c \text { and } n>0
$$


Where $c$ is a fixed constant. The constraint in (8) is the aggregation of the company cost constraint and the employee value constraint used in Henderson (2005).

Similar to that in (7), this optimization problem was solved numerically. In this analysis, $c$ was chosen such that for retained parameters, the number of granted at-the-money options $n$ is around 1000 , hence total cost of $€ 28$ 333. Once $c$ is set, $n$ is determined from the constraint in (8) for a given strike price $K \neq S$, then total incentives $\frac{\partial n C_{\theta, a}(K)}{\partial S}$ are assessed. These are depicted in figure 8 .

The left-hand side sub-figure exhibits total incentives for different levels of $K$ and probability weighting parameter $a$, with risk aversion held constant at $\lambda=2.25$. For each combination of $K$ and $a$ the constraint in (8) is solved for $n$, which allows to determine total incentives. The plots indicate that when the employee is deeply subject to probability weighting $(a \leq 0.475), \frac{\partial n C_{\theta, a}(K)}{\partial S}$ is strictly decreasing throughout the depicted range of strike prices (see the curves in blue). In this case, similar to EUT-based studies' findings (Hall and Murphy, 2002; Henderson, 2005), incentives are maximized through restricted stocks grant rather than stock options. The intuitive reason behind that is, given that the employee systematically values the options in excess of their BS value, efficient trade-off over compensation allocation is made via the grant of equity-based instruments that employee values at their actual cost, restricted stocks for instance.

However, for lower degrees of probability weighting (typically $0.475<a \leq 0.85$ ) the optimal strike price is not nil and tends to increase with $a$. Specifically, the optimization problem is defined on the right (see the red solid curve) or on the left (see the red dashed curve) of the optimal strike $K^{*}$ and $\frac{\partial n C_{\theta, a}(K)}{\partial S}$ admits an infinite branch in $K^{*}$ (i.e. total incentives are infinite at that point). The technical reason behind that is that the subjective value is equal to the BS value at the optimal strike, which yields according to the constraint in (8) an infinite grant size $\left(\lim _{K \rightarrow K^{*}} n(K)=+\infty\right)$. For instance, $K^{*}$ ranges from $60 \%$ to $195 \%$ when a takes values within a range of value around the experimental estimates $(0.55 \leq a \leq 0.70)^{11}$. This suggests that, depending on the extent to which employee weights probabilities, either grants of discount options or premium options may result in a Pareto optimum to the contract. As a specific example, for an employee with $a=0.616$, the optimal strike price $K^{*}$ is around $100 \%$, which means that, for the prevailing setting, the model predicts at-the-money options as optimal in an efficient contracting framework since the company's cost of granting these options is equal to their value to the employee. In this case, granting

\footnotetext{
${ }^{11}$ Optimal strikes are expected to be lower for higher stock price volatility since probability weighting effect tends to increase with volatility (recall figure 2).
} 
options with strike price around the stock price at inception, which is consistent with observed practices, results in a perfect reconciliation of the company and the employee respective views. Note that for a similar setting in the previous situation where the options are given as an add-on to existing compensation, the model indicates that incentives from stock options could be infinitely increased by granting increasingly more options at greater and greater strike price.

Furthermore, for weak degrees of probability weighting $(0.85<a)$, the subjective value of the option lies strictly below the BS value because the effect of loss-aversion tends to dominate that of probability weighting. Thus the total incentives function takes a non-monotone concave shape and shows finite extremas ranging from $35 \%$ to $81 \%$. In particular, when probability weighting assumption is relaxed ( $a=1)$, the function flattens around the maximum and approaches a monotone decreasing shape with increasing loss-aversion (see sub-figure on the right-hand side). This result suggests that loss-averse employees who are not subject to probability weighting - even with very low degree of probability weighting - receiving options at high exercise price would willingly accept a cut in cash compensation to receive instead deep discount options or restricted shares for those of them displaying more loss-aversion. Again, this is broadly consistent with Hall's and Murphy's (2002) and Henderson's (2005) findings for non-diversified risk-averse employees.

Last but not least, the sub-figure in the middle of the main figure is plots of total incentives against the strike price; each of them corresponds to a given level of loss-aversion. The purpose of this analysis consists in showing the effect of loss-aversion on $K^{*}$ by holding $a$ constant at 0.65 and varying $\lambda$. It mainly shows that loss-aversion has an effect opposite to that of probability weighting: when probability weighting effect is dominant ${ }^{12}$ (i.e. the employee may potentially put overstated value in the option, specifically for high strikes) optimal strike increases and total incentives decreased with loss-aversion. Conversely, when loss-aversion effect is dominant, as stated before, the model yields predictions comparable to that of the EUT-based models.

\footnotetext{
${ }^{12}$ See the limit case of $\lambda=1$ where risk-aversion is ignored (the blue dashed curve).
} 

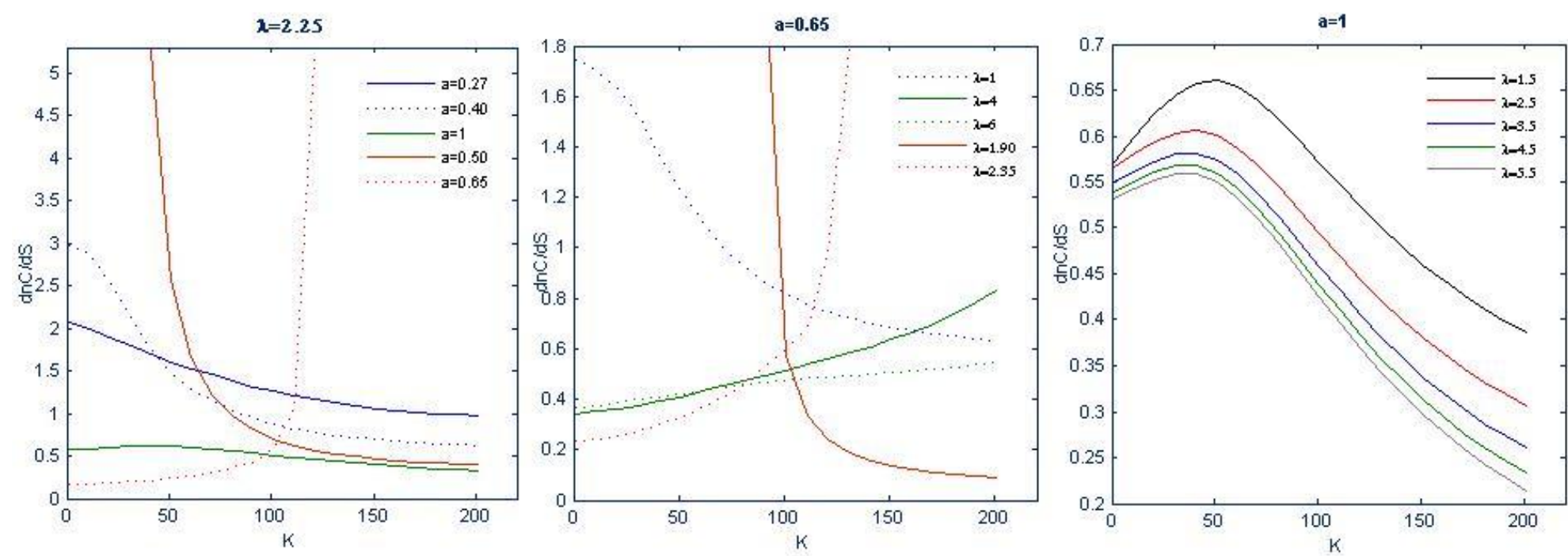

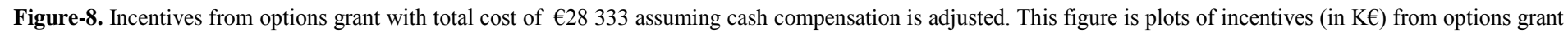

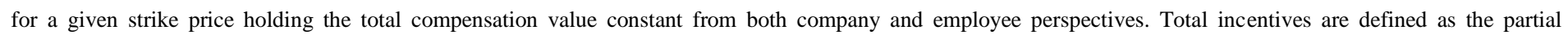

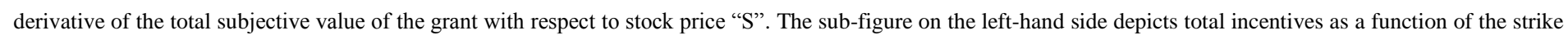

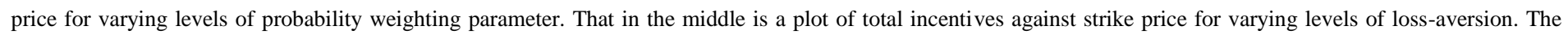

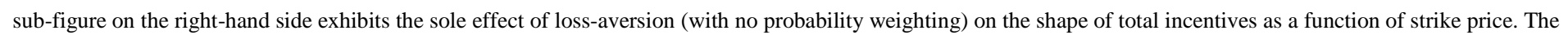
derivatives were computed numerically based on the following parameters: $\mathrm{T}=4 ; \sigma=30 \% ; \mathrm{S}=100 ; \mathrm{r}=3 \% ; \mathrm{q}=0 \% ; \alpha=0.88$.

\section{Do stock-options provide incentive for risk taking?}

Earlier studies (Agrawal and Mandelker, 1987; DeFusco et al., 1990; Hirshleifer and Suh, 1992) have built on insights from standard option pricing theory to predict that option-compensated managers will be motivated to increase the asset variance and leverage of their firms because the convexity of the option payoff increase its value as the volatility of the stock price increases. Lambert et al. (1991) was the first to call into question this assertion. They proved that a non-diversified riskaverse executive may not necessarily take actions that increase stock price volatility because that parameter of the distribution of the stock price has two conflicting effects on the subjective value of the option: a positive effect implied by the payoff convexity and a negative effect due to the concavity of the executive's utility function. Henderson (2005) draws conclusions from a EUT-base model consistent with these findings. Specifically, she finds that stock-options provide incentives for a riskaverse manager to increase the beta of the company (i.e. the market risk-to-firm specific risk ratio) rather than total risk. Although there is some empirical evidence supporting the prediction that stockoptions do not systematically encourage risk taking, it is still very scarce ${ }^{13}$.

\footnotetext{
${ }^{13}$ See for instance Cohen et al.(2000) and Rajgopal and Shevelin (2002).
} 
I revisited the risk taking incentives issue from the perspective of an executive with CPT preferences. Similar to previous studies, I defined incentives for risk taking as the first order derivative of the subjective value in (6) with respect to volatility $\left(\frac{\partial C_{\theta, a}}{\partial \sigma}\right)^{14}$. In order to figure out the link between risk-taking incentives from stock-options and the parameters related to preferences, I performed a numerical analysis on the sensitivity of $\frac{\partial C_{\theta, a}}{\partial \sigma}$ to loss-aversion and probability weighting. The results are reported in figure 8 hereafter.
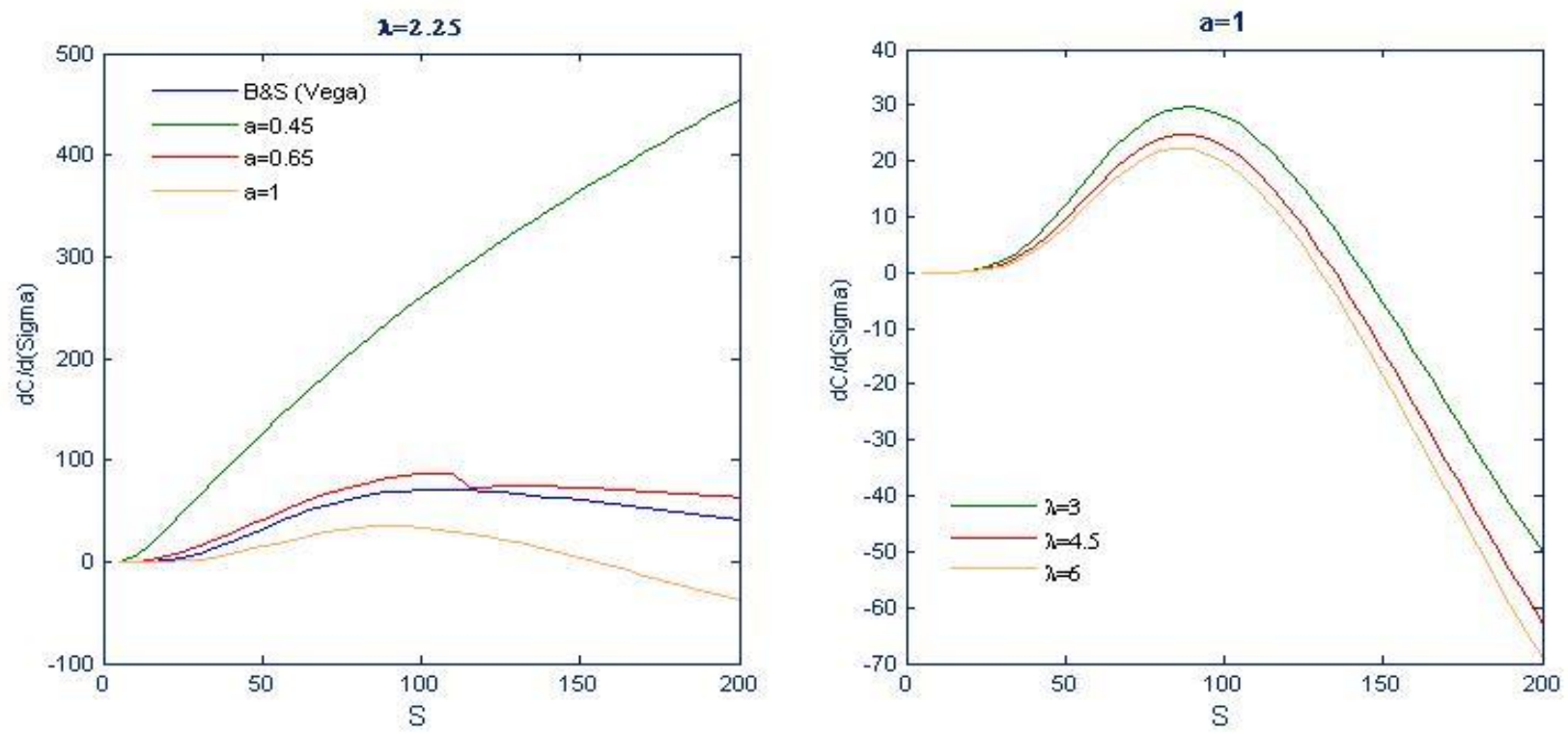

Figure-9. The effect of loss-aversion and probability weighting on risk-taking incentives implied by stock-options. This figure is plots of the partial derivative of the subjective value with respect to stock price volatility " $\sigma$ " against the option moneyness. It exhibits, on the one hand, the combined effects of loss-aversion and option moneyness (chart on the right-hand side) and, on the other hand, the combined effects of probability weighting and option moneyness (chart on the left-hand side) on risk-taking incentives. The derivatives were computed numerically assuming three different levels of loss-aversion and probability weighting (see the legends above) and holding the remaining parameters constant at the following values: $\mathrm{T}=4 ; \sigma=30 \% ; \mathrm{K}=100 ; \mathrm{r}=3 \% ; \mathrm{q}=0 \% ; \alpha=0.88$.

The left-hand side subfigure is plots of $\frac{\partial C_{\theta, a}}{\partial \sigma}$ as a function of the stock price for several degrees of probability weighting with loss-aversion held constant at $\lambda=2.25$. The purpose of the underlying analysis is to figure out broadly the extent to which a loss-averse executive subject to probability weighting would prefer a high or low risk given the way the latter influences the option value from his own perspective. The first essential result from this analysis is that incentives for risk taking are

\footnotetext{
${ }^{14}$ Actually, the sensitivity of the subjective value to a parameter of the probability distribution of the stock price provides a measure of the executive incentive to make decisions that influence that parameter.
} 
increasing with probability weighting degree. In fact, the probability weighting leverages the positive effect of volatility on the subjective value through the convexity of the option payoff. Another observation that could be made is that for sufficiently high degree of probability weighting $(a \leq 0.70) \frac{\partial C_{\theta, a}}{\partial \sigma}$ lies strictly above the conventional BS Vega over the retained range of stock prices (see the red and the green curves). This means that an option-compensated CPT-executive subject to probability weighting may be more prompted than a risk-neutral executive to act in order to increase assets volatility. Note that for typical setting of $a$ at 0.65 , the model predicts that a CPT-executive with a such preferences calibration will have incentives to act in order to increase the volatility of the stock price by $1 \%$ if he targets a $87 \mathrm{cts}$ - increase of the value of his at-the-money 4-year option.

In addition, when probability weighting is ignored by setting $a=1$, only the effect of loss-aversion on risk taking incentives is captured. The analysis of this effect is reported in the subfigure on the right-hand side. More explicitly, this subfigure exhibits plots of $\frac{\partial C_{\theta, a}}{\partial \sigma}$ for several levels of $\lambda$ with probability weighting effect neutralized. It shows mainly that risk-taking incentives from stock-options are decreasing with loss-aversion. Moreover, it appears that $\frac{\partial C_{\theta, a}}{\partial \sigma}$ turns negative over a given range of stock prices where the option is in-the-money. Therefore, consistent with findings from EUT-based models, the CPT model predicts that a loss-averse executive who is not subject to probability weighting may not prefer an increase in the variance of the company stock price return. As a specific example, an executive with a loss-aversion parameter $\lambda=6$, who processes probabilities in a linear way (see the yellow curve) and holds 4-year stock options, will have incentives to decrease rather than increase the volatility of the company stock price if the stock price is above $130 \%$ the strike price of his options.

In essence, incentives for risk taking from stock options - defined as the sensitivity of the subjective value to the stock price volatility - is subject to two opposite effects under the CPT-based model: a positive effect from the convexity of the option's payoff leveraged by the probability weighting feature and a negative effect from the loss-aversion coefficient. Therefore, there is a mixed effect on risk taking incentives depending on which of the two effects dominates. This will depend obviously on the option moneyness and the other option-specific parameters.

\section{Conclusion}

This paper proposes an alternative theoretical model of stock option subjective value to analyze their incentive effects for employees. The model predictions ascertain the ability of CPT to explain some prominent incentive patterns that EUT models have difficulties to capture. It mainly provides 
arguments on the well documented tendency of employees to frequently value - under some circumstances - their options in excess of their cost to the company. Specifically, these results highlight the economic rational for firms, in particular those with higher risk, to widely use stock options in non-executive employee compensation (Spalt, 2008).

Loss aversion and probability weighting are the key features driving the subjective value in the CPT model. These parameters have countervailing effects on the modeled subjective value. Depending on which of them is dominant in the preferences calibration, the model yields different predictions regarding incentives. Specifically, consistent with some behavioral patterns observed in many surveys and experimental studies on equity-based compensation, the model predicts that, when the probability weighting feature prevails, the subjective value may overstate the risk-neutral value of the option. In this case, assuming the company and the employee bargain efficiently over the compensation components, incentives are maximized for strike prices set around the stock price at inception for a representative employee with preferences calibration meeting the experimental estimates from CPT (Tversky and Kahneman, 1992). Obviously, this finding is consistent with companies' actual compensation practices. Moreover, executives with such preferences profile may be prompted to act in order to increase share price volatility. However, when the emphasis is put on the loss-aversion feature, by relaxing the probability weighting assumption, the model yields results comparable to those of EUT-based models. In particular, the model predicts that loss-averse employees who are not subject to probability weighting, or even with very low degrees of probability weighting, receiving options at high exercise price would willingly accept a cut in compensation to receive instead deep discount options or restricted shares for those of them displaying more loss-aversion. Furthermore, the model shows that loss-averse executives who are processing probabilities in a linear fashion may not prefer an increase in the variance of the company stock price return.

Despite their practical interest, the conclusions from the results of this research should not be drawn without underlining some of its limitations. The first one concerns the specification of the CPT model. Actually, although the reference point specification in the model is consistent with both empirical evidence on people setting reference points in a dynamic fashion and firms' widespread use of the BS value as a standard for Financial and Human Resources disclosers, empirical and experimental literature is still silent on how people set reference points when assessing complex gambles like stock option payoffs. In addition, to keep the model tractable, only European-style options were studied in this paper. The model is still however easily extendable to Bermudian-style options using numerical schemes such like lattice approaches. The other limitation of this study is related to the large heterogeneity in probability weighting that may exist across individuals ( $\mathrm{Wu}$ and Gonzalez, 1996). The Tversky's and Kahneman's (1992) weighting function used in the model provides only a fit to the median profile. 
Finally, this work highlights - as did some previous eminent researches in this field (Dittmann et al., 2008; Splat, 2008) - a number of future promising research directions in equity-based compensation incorporating CPT framework. For instant, exploring the ability of CTP to explain the growing use of performance shares plans instead of stock options in employee compensation would be of great interest for future research. Furthermore, given that several empirical studies has documented that employee stock option exercise behavior is also driven by behavioral factors, a promising research direction incorporating CPT is studying its ability to predict exercise patterns.

\section{Appendix A: proofs of proposition 1}

This appendix provides heuristic proofs of proposition 1.

To prove that the subjective value $C_{\theta, a}$ is decreasing in $a \in[0.28,1]$, it is sufficient to show that the expectation $E_{\theta, a}$ is a decreasing function of $a$. Let's first rewrite the expectation in (6) as follows:

$$
\begin{aligned}
E_{I P_{\Omega_{a}}}\left\{v_{\theta}\left(h_{T}\right)\right\} & =E_{I P_{\Omega_{a}}}\left\{v_{\theta} \circ h_{T} \circ g(x)\right\} \\
& =\int_{I R} w_{\theta}(x) \Omega_{a}^{\prime}\left(\int_{-\infty}^{x} \varphi(u) d u\right) \varphi(x) d x
\end{aligned}
$$

Where:

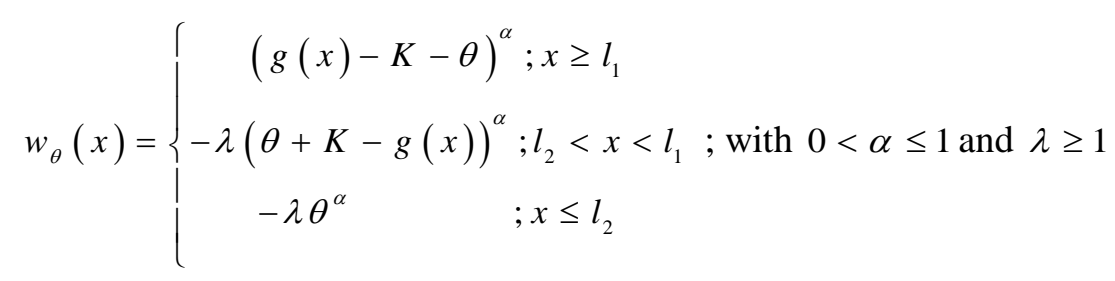

Since $w_{\theta}(x)$ is derivable over $I R \backslash\left\{l_{1}\right\}$, an expansion in Taylor series at the first order gives:

$$
w_{\theta}(x) \approx w_{\theta}(y)+(x-y) w_{\theta}^{\prime}(y) \text { with } y \in I R \backslash\left\{l_{1}\right\}
$$

Introducing the expectation operator with respect to the transformed probability measure, we have:

$$
\begin{aligned}
E_{I P_{\Omega_{a}}}\left(w_{\theta}(x)\right) & \approx w_{\theta}(y)+\left(E_{I P_{\Omega_{a}}}(x)-y\right) w_{\theta}^{\prime}(y) \\
& =w_{\theta}(y)+\left(E_{I P}\left(x \Omega_{a}^{\prime}\left(\int_{-\infty}^{x} \varphi(u) d u\right)\right)-y\right) w_{\theta}^{\prime}(y)
\end{aligned}
$$


Since $w_{\theta}(x)$ is monotone increasing in $x$, we have: $w_{\theta}^{\prime}(y) \geq 0$. Then it follows from (A.2) that proving that $E_{\theta, a}$ is locally decreasing with respect to $a$ in $y \in I R \backslash\left\{l_{1}\right\}$ boils down to showing that:

$$
\frac{\partial E_{I P}\left(x \Omega_{a}^{\prime}\left(\int_{-\infty}^{x} \varphi(u) d u\right)\right)}{\partial a} \leq 0
$$

Noting that $\Omega_{a}^{\prime}\left(\int_{-\infty}^{x} \varphi(u) d u\right)$ is positive and convex with respect to $\left.x \in\right]-\infty, l_{1}[\cup] l_{1},+\infty[$, we have according to Jensen inequality:

$$
E_{I P}\left(x \Omega_{a}^{\prime}\left(\int_{-\infty}^{x} \varphi(u) d u\right)\right) \geq E_{I P}(x) \Omega_{a}^{\prime}\left(\int_{-\infty}^{E_{I P}(x)} \varphi(u) d u\right)
$$

Since $x$ follows a standard normal distribution, which is symmetric in $E_{I P}(x)=0$, we get from the inequality above, by substituting $E_{I P}(x)$ in the right hand side:

$$
E_{I P}\left(x \Omega_{a}^{\prime}\left(\int_{-\infty}^{x} \varphi(u) d u\right)\right) \geq 0
$$

Note that the result in (A.4) above, showing that the expectation under the transformed probabilities overstates that under the original probabilities, is a consequence of the probability weighting function feature stated in $\$ 1.1 .2$, which consists in infinitely-overweighting infinitesimal probabilities and infinitely-underweighting near-one probabilities.

Furthermore, noting that the convexity of $\Omega_{a}^{\prime}\left(\int_{-\infty}^{x} \varphi(u) d u\right)$ with respect to $\left.x \in\right]-\infty, l_{1}[\cup] l_{1},+\infty[$ is decreasing in $a$, and using the result in (A.4) we have for $0.28<a<b \leq 1$ :

$$
E_{I P}\left(x \Omega_{a}^{\prime}\left(\int_{-\infty}^{x} \varphi(u) d u\right)\right)-E_{I P}(x) \Omega_{a}^{\prime}\left(\int_{-\infty}^{E_{I P}(x)} \varphi(u) d u\right) \geq E_{I P}\left(x \Omega_{b}^{\prime}\left(\int_{-\infty}^{x} \varphi(u) d u\right)\right)-E_{I P}(x) \Omega_{b}^{\prime}\left(\int_{-\infty}^{E_{I P}(x)} \varphi(u) d u\right)
$$

Or equivalently:

$$
E_{I P}\left(x \Omega_{a}^{\prime}\left(\int_{-\infty}^{x} \varphi(u) d u\right)\right) \geq E_{I P}\left(x \Omega_{b}^{\prime}\left(\int_{-\infty}^{x} \varphi(u) d u\right)\right)
$$


This proves that the condition in (A.3) holds, which means that $C_{\theta, a}$ is a decreasing function of $a \in[0.28,1]$. Q.E.D.

\section{Appendix B: proofs of proposition 2}

Taking the derivative of the subjective value function in (6) with respect to $\lambda$ yields:

$\frac{\partial C_{\theta, a}}{\partial \lambda}=\left\{\begin{array}{l}\frac{1}{\alpha} \frac{\partial E_{\theta, a}}{\partial \lambda}\left(E_{\theta, a}\right)^{\frac{1}{\alpha}-1} e^{-r T}, \text { if } E_{\theta, a} \geq 0 \\ -\frac{1}{\alpha \lambda}\left(-\frac{E_{\theta, a}}{\lambda}\right)^{\frac{1}{\alpha}-1}\left(\frac{E_{\theta, a}}{\lambda}-\frac{\partial E_{\theta, a}}{\partial \lambda}\right) e^{-r T}, \text { otherwise }\end{array}\right.$

Where:

$\frac{\partial E_{\theta, a}}{\partial \lambda}=\frac{\partial I_{\theta, a}^{1}}{\partial \lambda}+\frac{\partial I_{\theta, a}^{2}}{\partial \lambda}+\frac{\partial I_{\theta, a}^{3}}{\partial \lambda}$

Using the formulas in equations from (6.2) to (6.4), we can rewrite the derivatives in (B.2) as follows:

$$
\begin{aligned}
& \frac{\partial I_{\theta, a}^{1}}{\partial \lambda}=0 \\
& \frac{\partial I_{\theta, a}^{2}}{\partial \lambda}=-\int_{l_{2}}^{l_{1}}(K+\theta-g(x))^{\alpha} \Omega_{a}^{\prime}\left(\int_{-\infty}^{x} \varphi(u) d u\right) \varphi(x) d x \\
& \frac{\partial I_{\theta, a}^{3}}{\partial \lambda}=-\theta^{\alpha} \Omega_{a}\left(\int_{-\infty}^{l_{2}} \varphi(x) d x\right)
\end{aligned}
$$

Then substituting these results in place of the derivatives in (B.2) we obtain:

$$
\frac{\partial E_{\theta, a}}{\partial \lambda}=-\int_{l_{2}}^{l_{1}}(K+\theta-g(x))^{\alpha} \Omega_{a}^{\prime}\left(\int_{-\infty}^{x} \varphi(u) d u\right) \varphi(x) d x-\theta^{\alpha} \Omega_{a}^{\prime}\left(\int_{-\infty}^{l_{2}} \varphi(x) d x\right)
$$

Given that $\frac{\partial E_{\theta, a}}{\partial \lambda} \leq 0$, we conclude that $\frac{\partial C_{\theta, a}}{\partial \lambda}$ is nonpositive. This implies that $C_{\theta, a}$ is a decreasing function of $\lambda$. Q.E.D. 


\section{References}

Abdellaoui, M. (2000), "Parameter-Free Elicitation of Utility and Probability Weighting Functions", Management Science, Vol. 46 No. 11, pp. 1497-1512.

Agrawal, A., Mandelker, G. (1987), "Managerial incentives and corporate investment and financing decisions", Journal of Finance, Vol. 42 No. 4, pp. 823-837.

Bahaji, H. (2009), "Le comportement d'exercice des porteurs de stock-options: une étude empirique sur le marché Américain", Working Paper, DRM Finance- Université de Paris Dauphine, Paris, June 2009.

Barberis, N. and Thaler, R.(2003), "A survey of behavioral finance", in Constantinides, G., Harris, M., and Stulz, R. (Ed.), Handbook of the Economics of Finance, North-Holland, Amsterdam.

Bleichrodt, H. and Pinto, J.L. (2000), "A Parameter-Free Elicitation of the Probability Weighting Function in Medical Decision Analysis", Management Science, Vol. 46 No. 11, pp. 1485-1496.

Cai, J. and Vijh, A.M. (2004), "Executive stock and option valuation in a two state variable framework: allowing optimal investment of outside wealth in the risk-free asset and the market portfolio", Working Paper, University of Iowa.

Camerer, C. and Ho, T.H. (1994), "Violations of Betweenness Axiom and Nonlinearity in Probability", Journal of Risk and Uncertainty, Vol.8 No. 2, pp. 167-196.

Cohen, R.B., Hall, B.J. and Viceira, L.M. (2000), "Do executive stock options encourage risk taking ?", Working Paper, Harvard Business School.

Cook, P. and Clotfelter, C. (1993), "The peculiar scale economies of lotto", American Economic Review, Vol. 83 No.3 , pp. 634-643.

DeFusco, R., Johnson, R. and Zorn, T. (1990), "The effect of executive stock option plans on stockholders and bondholders", Journal of Finance, Vol.45 No. 2, pp. 617-627.

Detemple, J. and Sundaresan, S. (1999), "Nontraded asset valuation with portfolio constraints: a binomial approach", Review of Financial Studies, Vol. 12 No. 4, pp. 835-872.

Devers, C., Wiseman, R. and Holmes, M. (2007), "The effects of endowment and loss aversion in managerial stock option valuation", Academy of Management Journal, Vol. 50 No. 1, pp. 191-208.

Dittmann, I. and Maug, E. (2007), "Lower salaries and no options? On the optimal structure of Executive pay”, The Journal of Finance, Vol. 62 No. 1, pp. 303-343.

Gneezy, U. (1998), "Updating the Reference Level: Experimental Evidence", Working paper, University of Haifa.

Hall, B. and Murphy, K. (2000), "Optimal Exercise prices for executive stock options", American Economic Review, Vol. 90 No. 2, pp. 209-214. 
Hall, B. and Murphy, K. (2002), "Stock options for undiversified executives", Journal of Accounting and Economics, Vol. 33 No. 2, pp. 3-42.

Hallock, K. and Olson, G. (2006), "The value of stock options to non-executive employees", Working Paper, No. 11950, National Bureau of Economic Research, Cambridge.

Heath, C., Huddart, S. and Lang, M. (1999), "Psychological factors and stock option exercise", Quarterly Journal of Economics, Vol. 114 No. 2, pp. 601-628.

Heisler, J.(1994), "Loss aversion in a futures market: an empirical test", Review of Futures Markets, Vol. 13 No. 3, pp. 793-822.

Henderson, V. (2005), The impact of the market portfolio on the valuation, incentives and optimality of executive stock options, Quantitative Finance, Vol. 5 No. 1, pp. 35-47.

Hirshleifer, D. and Suh, R. (1992), "Risk, Managerial Effort, and Project Choice", Journal of Financial Intermediation, Vol. 2 No. 3, pp. 308-345.

Hodge, F. Rajgopal, S. and Shevlin, T. (2006), "How do managers value stock options and restricted stock ?", Working Paper, University of Washington.

Holmstrom, B.R. and Milgrom, P.R. (1987), "Aggregation and linearity in provision of intertemporal incentives", Econometrica, Vol. 55 No. 2, pp. 303-328.

Huddart, S. and Lang, M. (1996), "Employee stock option exercises: an empirical analysis", Journal of Accounting and Economics, Vol. 21 No. 1, pp. 5-43.

Jensen, M. and Murphy, K.J. (1990), "Performance pay and top-management incentives", Journal of Political Economy, Vol. 98 No. 2, pp. 225-264.

Jenter, D. (2001), "Understanding high-powered incentives", Working Paper, Harvard Business School and Economics Departement.

Johnson, S.A. and Tian, Y.S. (2000), "The value and incentive effects of non-traditional executive stock option plans", Journal of Financial Economics, Vol. 57 No. 1, pp. 3-34.

Jullien, B; and Salanie, B. (2000), "Estimating preferences under risk: The case of racetrack bettors", Journal of Political Economy, Vol. 108 No. 3, pp. 503-530.

Kachelmeier, S. and Shehata, M. (1992), "Examining risk preferences under high monetary incentives: experimental evidence from the People's Republic of China", American Economic Review, Vol. 82 No. 5, pp. 1120-1141.

Kahneman, D. and Tversky, A. (1979), "Prospect Theory: An analysis of decision under risk", Econometrica, Vol. 47 No. 2, pp. 263-292.

Lambert, R., Lanen, W. and Larcker, D. (1989), "Executive stock option plans and corporate dividend policy", Journal of Financial and Quantitative Analysis, Vol. 24 No. 4, pp. 409-424.

Lambert, R., Larcker, D. and Verrecchia, R. (1991), "Portfolio considerations in valuing Executive Compensation", Journal of Accounting Research, Vol. 29 No. 1, pp. 129-149.

Lambert, R. and Larcker, D. (2001), "How do employees value (often incorrectly) their stock options", available at: knowledge@wharton. 
Lewellen, W., Loderer, C. and Martin, K. (1987), "Executive compensation and executive incentive problem: an empirical analysis", Journal of Accounting and Economics, Vol. 9 No. 3, pp. 287-310.

Loughran, T. and Ritter, J. (1995), "The new issue puzzle", Journal of Finance, Vol. 50 No. 1, pp. 2351 .

Markowitz, H. (1952), “The utility of wealth”, Journal of Political Economy, Vol. 60 No. 2, pp. 151158.

Odean, T. (1998a), “Are Investors Reluctant to Realize their Losses?”, Journal of Finance, Vol. 53 No. 5, pp. 1775-1798.

Rajgopal, S. and Shevlin, T. (2002), "Empirical evidence on the relation between stock option compensation and risk asking", Journal of Accounting and Economics, Vol. 33 No. 2, pp. 145-171.

Shefrin, H. and Statman, M. (1985), "The disposition to sell winners too early and ride losers too long: theory and evidence", Journal of Finance, Vol. 40 No. 3, pp. 777-790.

Sawers, K., Wright, A. and Zamora, V. (2006), "Loss aversion, stock-based compensation and managerial risk-seeking behavior", paper presented at the AAA 2007 Management Accounting Section Meeting, available at: http://ssrn.com/ abstract $=864224$

Thaler, R. (1999), "Mental Accounting Matters", Journal of Behavioral Decision Making, Vol. 12 No. 3, pp. 183-206.

Thaler, R. and Ziemba, W. (1988), "Parimutuel betting markets: Racetracks and lotteries", Journal of Economic Perspectives, Vol. 2 No. 2, pp. 161-174.

Tversky, A. and Kahneman, D. (1992), "Advances in Prospect Theory: Cumulative representation of uncertainty", Journal of Risk and Uncertainty, Vol. 5 No. 4, pp. 297-323.

Yermack, D. (1997), "Good Timing: CEO Stock Option Awards and Company News Announcements", Journal of Finance, Vol. 52 No. 2, pp. 449-476.

Wu, G. and Gonzalez, R. (1996), "Curvature of the Probability Weighting function", Management Science, Vol. 42 No. 12, pp. 1676-1690. 